\title{
Influence of Alternanthera brasiliana (L.) Kuntze on Altered Antioxidant Enzyme Profile during Cutaneous Wound Healing in Immunocompromised Rats
}

\author{
Chandana Choudhury Barua, ${ }^{1}$ Shameem Ara Begum, ${ }^{2}$ Archana Talukdar, ${ }^{3}$ \\ Jayanti Datta Roy, ${ }^{1}$ Bhaben Buragohain, ${ }^{1}$ Debesh Chandra Pathak, ${ }^{2}$ Dilip Kumar Sarma, ${ }^{4}$ \\ Rumi Saikia Bora, ${ }^{5}$ and Asheesh Gupta ${ }^{6}$ \\ ${ }^{1}$ Department of Veterinary Pharmacology \& Toxicology, College of Veterinary Science, Assam Agricultural University, Khanapara, \\ Guwahati 781022, India \\ ${ }^{2}$ Department of Veterinary Pathology, College of Veterinary Science, Assam Agricultural University, Khanapara, \\ Guwahati 781022, India \\ ${ }^{3}$ Department of Veterinary Medicine, Public Health \& Hygiene, College of Veterinary Science, Assam Agricultural University, \\ Khanapara, Guwahati 781022, India \\ ${ }^{4}$ Department of Veterinary Microbiology, College of Veterinary Science, Assam Agricultural University, Khanapara, \\ Guwahati 781022, India \\ ${ }^{5}$ Department of Livestock Production and Management, College of Veterinary Science, Assam Agricultural University, \\ Khanapara, Guwahati 781022, India \\ ${ }^{6}$ Department of Biochemical Pharmacology, Defence Institute of Physiology and Allied Sciences, New Delhi 110054, India
}

Correspondence should be addressed to Chandana Choudhury Barua, chanacin@gmail.com

Received 30 April 2012; Accepted 10 June 2012

Academic Editors: G. M. Campo and D. K. Miller

Copyright ( 2012 Chandana Choudhury Barua et al. This is an open access article distributed under the Creative Commons Attribution License, which permits unrestricted use, distribution, and reproduction in any medium, provided the original work is properly cited.

Alternanthera brasiliana (L.) Kuntze (Amaranthaceae) is a herbaceous plant used against inflammation, cough, and diarrhea in Brazilian popular medicine. In our preliminary study, promising wound healing activity of methanol extract of leaves of $A$. brasiliana (MEAB) was observed in normal excision and incision wound models. Therefore, the present study was designed to investigate the wound healing activity along with the antioxidant enzyme profile during cutaneous excision immunocompromised wound after topical application of $5 \% \mathrm{w} / \mathrm{w}$ ointment of MEAB in rats. Immunocompromised state was induced by pretreatment with hydrocortisone (HC) at $40 \mathrm{mg} / \mathrm{kg}$ body weight (i.m.) in male rats. Following one-week pretreatment with HC, wounds were created. The vehicle, $5 \%(\mathrm{w} / \mathrm{w})$ ointment of MEAB, or standard drug (Himax) was applied topically twice daily. Healing potential was evaluated by the rate of wound contraction, estimation of enzymatic and nonenzymatic antioxidants like catalase, SOD, GSH, protein, vitamin C, and hydroxyproline content, which was supported by histopathological study on the 8th day following wounding. There was significant increase in the enzymatic and nonenzymatic antioxidant parameters in the extract-reated group as compared to control group. Histopathological study revealed collagen deposition, fibroblast proliferation, angiogenesis, and development of basement membrane in A. brasiliana group. The results of the present investigation revealed significant wound healing activity of MEAB.

\section{Introduction}

Immunocompromised patients are susceptible to bacterial, fungal, and viral infections that healthy immune systems usually conquer. They are also susceptible to common infections of childhood. Often, the symptoms tend to be worse. There are several reasons such as chemotherapy and radiation that weakens the immune system. Chemotherapy and 
radiation treatments can harm or destroy white blood cells such as T cells, B cells, and neutrophils-key components of the immune system. The patient is immunocompromised because of powerful treatments for cancer or blood disorders that leave the immune system severely weakened. The patient is immunocompromised either because of an acquired or inherited immune deficiency disorder. Some cancers are associated with immune problems that predispose patients to certain infections.

Skin healing is a complex process that involves inflammation, reepithelization, angiogenesis, granulation tissue formation, and deposition of interstitial matrix, besides other events carried out by different types of cells, such as keratinocytes, fibroblasts, and inflammatory and endothelial cells. These phenomena are influenced by the interstitial matrix, growth factors, and other mediators [1]. It is believed that glucocorticoids hinder the cicatrisation process, likely causing a decrease in cellular proliferation, in neovascularization, and in matrix production [2]. In animals, a delay in the afflux of macrophages, neutrophils, and fibroblasts was reported. It is owned that corticosteroids suppress the inflammatory phase of wound healing [2]. It is possible that the chronic use of corticoids influences negatively the reepithelization, neovascularization, and collagen synthesis [3]. The effect of prolonged use of corticotherapy on surgical wound healing shows conflicting results in the literature. Several factors participate in this controversy, depending on the type and dosage of corticosteroids used, species of animals studied, duration of treatment, and methods of evaluation of healing efficacy [4]. Hence, the present study is undertaken to study the healing efficacy of a very effective and multifarious medicinal plant of north east India in various types of wounds like immunocompromised model after priming the animals with hydrocortisone therapy. The plant Alternanthera brasiliana Kuntze (L.) (Amaranthaceae) is a herbaceous plant commonly known in Brazil as penicillin or Joy weed due to its diverse medicinal properties. After validation of its wound healing activity in normal excision and incision wound, angiogenesis, and antioxidant property, [5] we have carried out studies on its healing efficacy in diabetic or burn wound models (communicated). In this paper immunocompromised animals were used as model as this condition also needs urgent attention of the clinician and researchers for the reasons mentioned above.

The plant is used against inflammation, cough, and diarrhea in Brazilian popular medicine [6]. The extracts of $A$. brasiliana exhibited antinociceptive effects in mice [7], antimicrobial effect [8], and also anti-herpes-simplex-virus activity [9]. Aqueous or ethanolic extracts of A. brasiliana were able to block human mitogen-induced lymphocyte proliferation without any toxic effect [10]. In our previous study, we have reported antinociceptive [11] activity of this plant in its methanol extract.

\section{Materials and Methods}

2.1. Plant Material. Leaves of A. brasiliana were collected from the medicinal garden of the Department of Pharmacology \& Toxicology, College of Veterinary Science, Khanapara during the months of February-June, 2010. Taxonomist Dr. I. C. Barua, Department of Agronomy AAU, Jorhat identified the plant and a voucher specimen (AAU/CVSc/PHT/02) was deposited in the herbarium.

2.2. Preparation of Methanol Extract. The leaves were washed with water, air-dried, and powdered in an electric blender. About $250 \mathrm{~g}$ of powdered leaves was soaked in $1000 \mathrm{~mL}$ methanol for 72 hours in a beaker, and the mixture was stirred every 18 hours using a sterile glass rod. Filtrate was obtained after passing through a fine muslin cloth and then by filter paper (Whatman No 1) three times. It was then concentrated in Rotary evaporator (Equitron, Roteva) at $50^{\circ}-60^{\circ} \mathrm{C}$ under reduced pressure. A dark brown methanol extract obtained was stored in air tight container at $4^{\circ} \mathrm{C}$ till further use. Yield was $6.12 \%(\mathrm{w} / \mathrm{w})$ in terms of dry leaves.

2.3. Phytochemical Screening. Preliminary qualitative phytochemical screening of the plant extract was done for the presence of various active principles [12].

2.4. Drugs and Chemicals. Ointment of three different concentrations was prepared by mixing $2.5,5.0$, and $7.5 \mathrm{~g}$ of MEAB with $97.5,95$, and $92.5 \mathrm{~g}$ of white soft petroleum jelly (S. D. Fine Chemicals, India) to prepare 2.5, 5.0, and 7.5\% ointment (w/w) of MEAB. Himax (Indian Herbs Research \& Supply Co. Ltd. Darra Shivpuri, Saharanpur) was used as standard drug. Its constituents are Indradaru and Somvalka. Effcorlin (Hydrocortisone sodium succinate, GSK, Mumbai, India) was used to produce immunocompromised status.

2.5. Experimental Animals. Healthy adult Swiss albino mice of either sex, approximately of the same age, weighing 25$30 \mathrm{~g}$, and adult Sprague Dawley rats of either sex weighing 180-200 g were used for the study. They were housed under controlled conditions of temperature $\left(25 \pm 3^{\circ} \mathrm{C}\right)$, humidity $(50 \pm 5 \%)$, and 12-hour light-dark cycles with food and water ad lib. Animals were housed individually in polypropylene cages containing sterile paddy husk bedding. The experiments were performed as per guidelines of the Institutional Animal Ethical Committee (770/03/ac/CPCSEA/FVScAAU/ IAEC/06/21) and conform to the national guidelines on the care and use of laboratory animals, India. Animals were periodically weighed before and after experiments. All the animals were closely observed for any infection and those which showed signs of infection were separated and excluded from the study.

2.6. Determination of $L D_{50}$ and Acute Toxicity. The $\mathrm{LD}_{50}$ of $A$. brasiliana was estimated by following up-and-down stair case method in mice using OECD TG-425 guidelines. Animals were observed hourly for 6 hours and again after 24 hours. The parameters for motor activity and gross effect were determined after administration of $A$. brasiliana orally at a dose of $2.0 \mathrm{~g} / \mathrm{kg}$ body weight. 
TABLE 1: Effect of topical application of MEAB on wound area contraction $\left(\mathrm{mm}^{2}\right)$ and percent wound contraction in immunocompromised rats.

\begin{tabular}{lcc}
\hline \multirow{2}{*}{ Treatment } & Area of wound $\left(\mathrm{mm}^{2}\right)$ in pre- and posttreatment period (\% wound contraction) \\
& Day 0 & Day 8 \\
\hline \multirow{2}{*}{ Control } & $57.33 \pm 2.26$ & $34.83 \pm 2.82$ \\
& $(0.00)$ & $(39.25)$ \\
MEAB & $63.33 \pm 2.16^{*}$ & $14.50 \pm 1.54^{*}$ \\
& $(0.00)$ & $(77.10)$ \\
Standard & $59.17 \pm 2.52$ & $23.67 \pm 1.84^{*}$ \\
& $(0.00)$ & $(60.00)$ \\
\hline
\end{tabular}

Values are mean \pm S.E., $N=6$, means bearing same superscript “*” in rows represents $P<0.05$ versus vehicle are significant.

2.7. Immunocompromised Wound Model. Immunocompromised state was induced by pretreatment with hydrocortisone (HC) at $40 \mathrm{mg} / \mathrm{kg}$ body weight (i.m.) in male rats. Following one-week pretreatment with $\mathrm{HC}$, the animals were anesthetized by intraperitoneal (i.p.) injection of thiopentone $(25 \mathrm{mg} / \mathrm{kg})$. The dorsal surface of the rat was shaved and the underlying skin was cleaned with $70 \%$ ethanol. The excision wounds [13] were made by excising the full thickness circular skin (approximately $60 \mathrm{~mm}^{2}$ ) on the preshaved dorsal surface of the rats. Animals were allowed to recover from anesthesia and housed individually in sterile cages. Administration of $\mathrm{HC}$ at a dose of $40 \mathrm{mg} / \mathrm{kg}$, i.m., daily, was continued in rats until the end of the experiment [3]. HC was freshly prepared in sterile, pyrogen-free distilled water (Lab. Vifor, India Pvt. Ltd, Bombay, India).

2.8. Experimental Design. A preliminary study was conducted for selection of the most effective concentration of MEAB ointment by using 2.5, 5.0, and 7.5\% (w/w) ointment for topical application. As 5\% (w/w) ointment showed optimum wound healing activity, it was selected for further detail study.

The experimental animals (rats) were randomly allocated into three groups of 6 animals each. Group I served as control and the rats received topical application of the vehicle, that is, soft white petroleum jelly, twice daily for 7 days. Animals of groups II and III received topical application of 5\% (w/w) ointment of $A$. brasiliana and positive control drug, that is, Himax ointment, respectively, twice daily for 7 days.

2.9. Wound Healing Potential. The wound surface area was measured by tracing its contours using a transparent paper on the 8th day, following wounding before wound excision to determine wound contraction. The area $\left(\mathrm{mm}^{2}\right)$ within boundary was measured planimetrically [14]. The percent wound contraction was calculated using the following formula:

$$
\frac{(\text { Initial wound size }- \text { specific day wound size })}{\text { Initial wound size }} \times 100 \text {. }
$$

The granulation tissue was excised on the 8th following wounding day to analyze prohealing biochemical parameters, namely, hydroxyproline [15] and total protein contents [16]. A 10\% homogenate of granulation tissue was prepared in $0.15 \mathrm{M} \mathrm{KCl}$ containing $5 \mathrm{mM}$ EDTA. After homogenization, samples were sonicated (Labsonic P, Germany) ten bursts of $5 \mathrm{sec}$ each at $5 \mathrm{sec}$ intervals and an aliquot was withdrawn for estimation of reduced glutathione (GSH) [17]. In the remaining homogenate, triton $\mathrm{X}-100$ was added at $0.1 \%(\mathrm{v} / \mathrm{v})$. Then, the samples were incubated at $4^{\circ} \mathrm{C}$ for 2.5 hours and centrifuged at $4226 \mathrm{~g}$. The supernatant was used for estimation of superoxide dismutase (SOD) [18], catalase (CAT) [19], and vitamin C content [20].

2.10. Histopathological Study. For histological studies, granulation tissues collected on the eighth day were fixed in $10 \%$ neutral formalin solution and dehydrated with a sequence of ethanol-xylene series of solution. The materials were processed by conventional paraffin embedding method. Microtome sections were prepared at $6 \mu$ thicknesses, mounted on glass slides, and stained with hematoxylin and eosin [20] and Van Geison's stain [21], followed by observation for histopathological changes under light microscope.

2.11. Statistical Analysis. Data were expressed as mean \pm $\mathrm{SE}$, and statistical significance between experimental and control values was analyzed by one-way ANOVA followed by Dunnett's test using Graph Pad Prism 2.01 (Graph Pad Software Inc., La Jolla, CA, USA). $P<0.05$ was considered statistically significant.

\section{Results}

3.1. Phytochemical Screening. A. brasiliana showed the presence of alkaloid by Wagner's and Dragendorff's test, steroid by Salkowski's and Liebermann-Burchard's test, and triterpenes by Salkowski's and Liebermann-Burchard's test.

3.2. $L D_{50}$ and Acute Toxicity Studies. In acute toxicity study, there was no change in motor activity and gross behaviour during $24 \mathrm{~h}$ of observation and the extract was found to be safe up to $2000 \mathrm{mg} / \mathrm{kg}$ body weight, p.o. The low toxicity of the plant observed in this study suggests that the plant extract is safe and did not affect any of the parameters studied.

3.3. Wound Healing Potential. Significant wound healing activity was observed in animals treated with $5 \%(\mathrm{w} / \mathrm{w})$ ointment of A. brasiliana in the immunocompromised wound. 


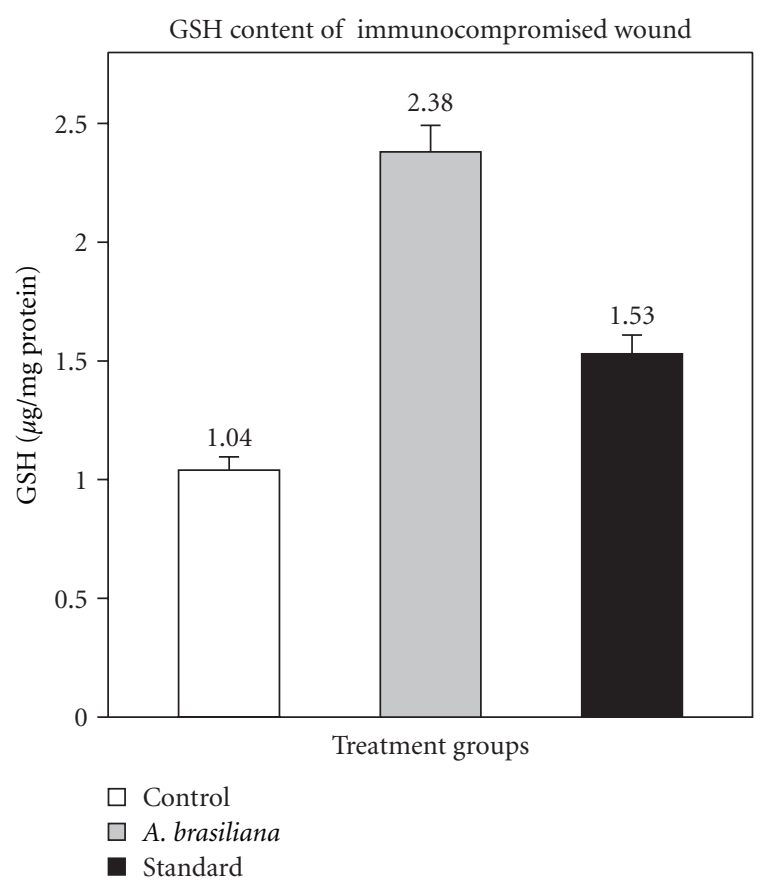

FIGURE 1: Effect of MEAB on reduced glutathione (GSH) content of granulation tissues in immunocompromised rats $(n=6$, each bar represents mean $\pm \mathrm{SE}, P<0.05$ versus vehicle, one-way ANOVA).

Percent wound contraction on the 8th day in the extracttreated group was $77.10 \%$, which was significantly $(P<$ $0.05)$ higher compared to the control $(39.25 \%)$ and standard $(60.00 \%)$ groups (Table 1$)$.

3.4. Antioxidant Parameters. The level of various enzymatic and nonenzymatic antioxidants increased significantly $(P$ $<0.05)$ in the granulation tissue of $A$. brasiliana-treated group as compared to the vehicle-treated control group. The level of reduced glutathione (GSH) was recorded to be $2.38 \pm 0.11 \mu \mathrm{g} / \mathrm{mg}$ protein in the A. brasiliana-treated group compared to $1.04 \pm 0.06 \mu \mathrm{g} / \mathrm{mg}$ protein in the control group (Figure 1). Similarly, antioxidant activities of SOD and CAT in granulation tissue of extract-treated animals (Figures 2 and 3$)$ also increased significantly $(P<0.05)$ in comparison to the vehicle-treated control animals. Protein content of the granulation tissues on the 8th day following wounding in A. brasiliana-treated group was $129.50 \pm 2.17 \mathrm{mg} / \mathrm{g}$ tissue, whereas, in the control group, it was $85.17 \pm 2.83 \mathrm{mg} / \mathrm{g}$ tissue (Figure 4). The hydroxyproline and vitamin $\mathrm{C}$ content of the granulation tissues were significantly higher $(P<0.05)$ in the group treated with $5 \%(\mathrm{w} / \mathrm{w})$ of MEAB than the control and Himax treated standard group (Figures 5 and 6).

3.5. Histopathological Study. Histopathological changes of the granulation tissues of control, A. brasiliana-treated, and standard groups in immunocompromised wounds are shown in Figures $7(\mathrm{a})-7(\mathrm{e})$. The control group showed necrosis and polymorphonuclear cell infiltration (H\&E $\times$

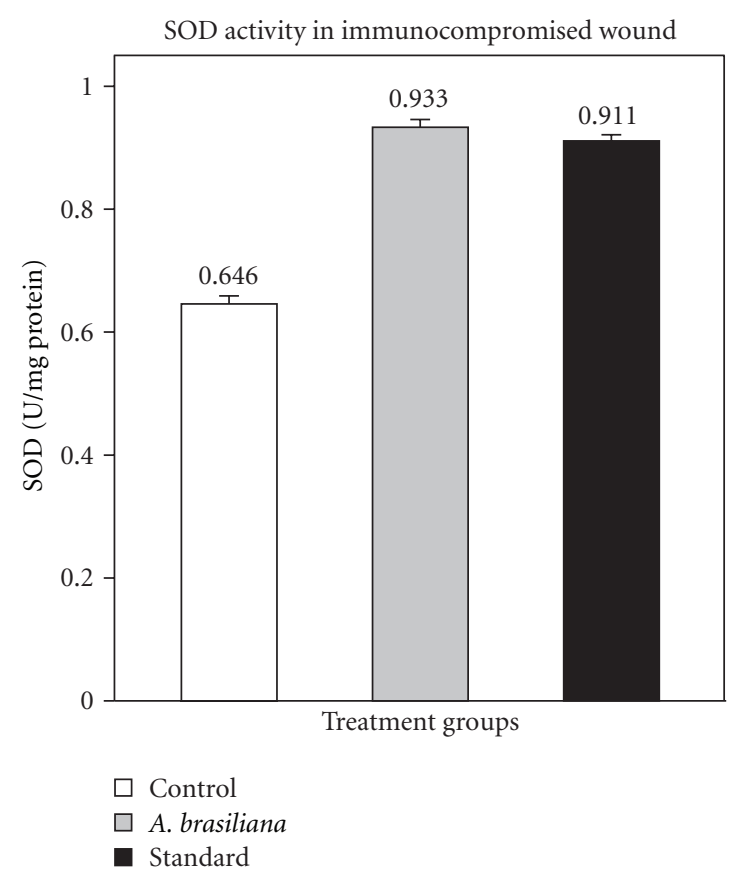

FIGURE 2: Effect of methanol extract of Alternanthera brasiliana on super oxide dismutase (SOD) activity of granulation tissues in immunocompromised rats $(n=6$, each bar represents mean \pm SE, $P<0.05$ versus vehicle, one-way ANOVA).

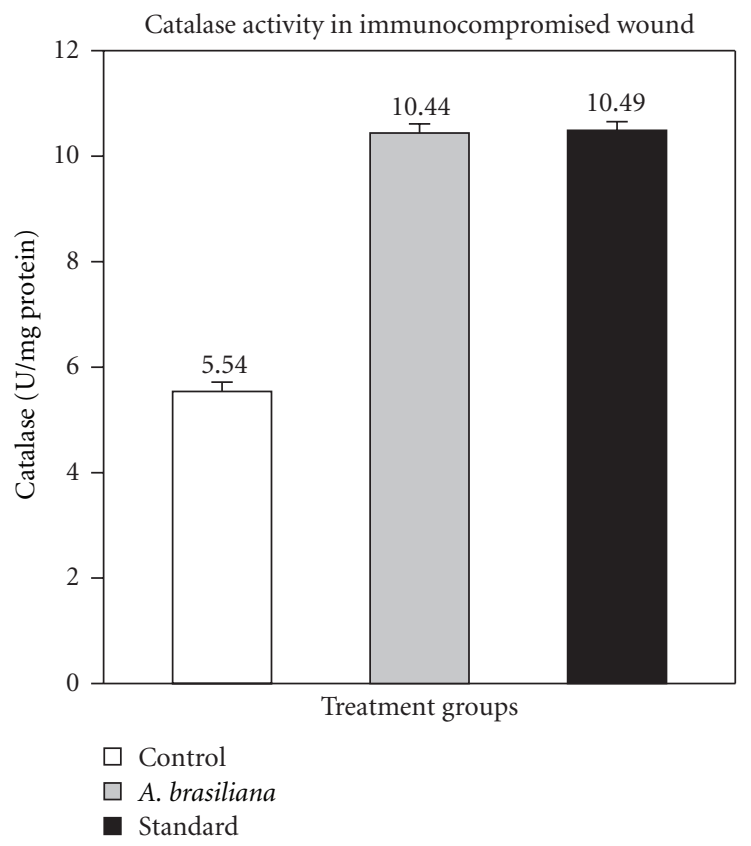

FIGURE 3: Effect of methanol extract of Alternanthera brasiliana on catalase (CAT) activity of granulation tissues in immunocompromised rats $(n=6$, each bar represents mean $\pm \mathrm{SE}, P<0.05$ versus vehicle, one-way ANOVA).

400) (Figure 7(a)), whereas granulation tissue of A. brasiliana-treated group showed abundance of collagen fibers (Van Gieson's $\times 100)$ (Figure 7(b)), fibroblast proliferation, angiogenesis $(\mathrm{H} \& \mathrm{E} \times 100)($ Figure $7(\mathrm{c}))$, and development of 


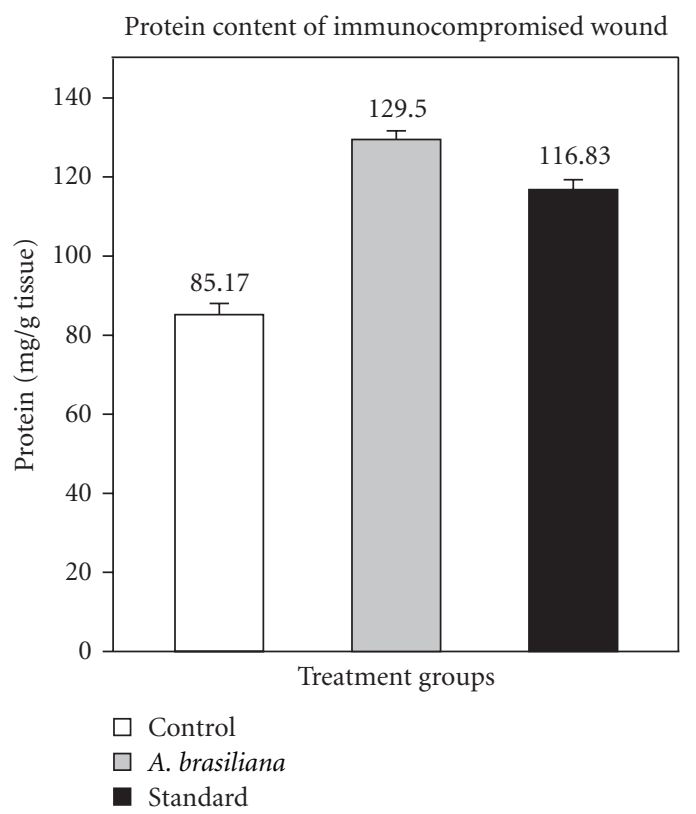

FIGURE 4: Effect of methanol extract of Alternanthera brasiliana on protein content of granulation tissues in immunocompromised rats ( $n=6$, each bar represents mean \pm SE, $P<0.05$ versus vehicle, oneway ANOVA).

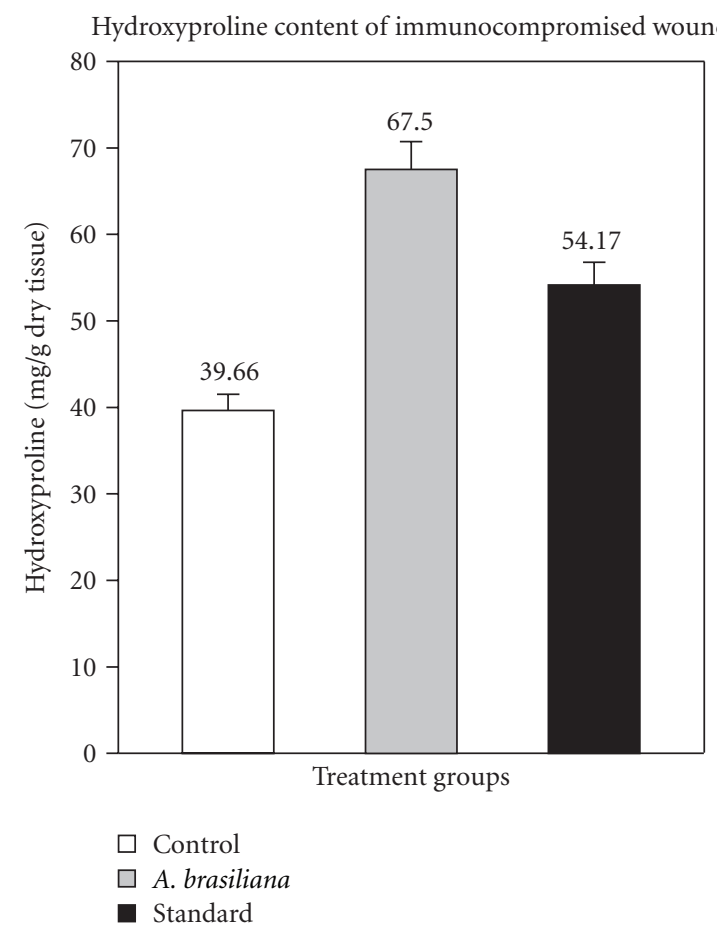

Figure 5: Effect of methanol extract of Alternanthera brasiliana on hydroxyproline content of granulation tissues in immunocompromised rats $(n=6$, each bar represents mean \pm SE, $P<0.05$ versus vehicle, one-way ANOVA).

basement membrane below the necrotic debris (Figure 7(d)) indicating wound healing activity of $A$. brasiliana. The granulation tissue of Himax-treated standard group on

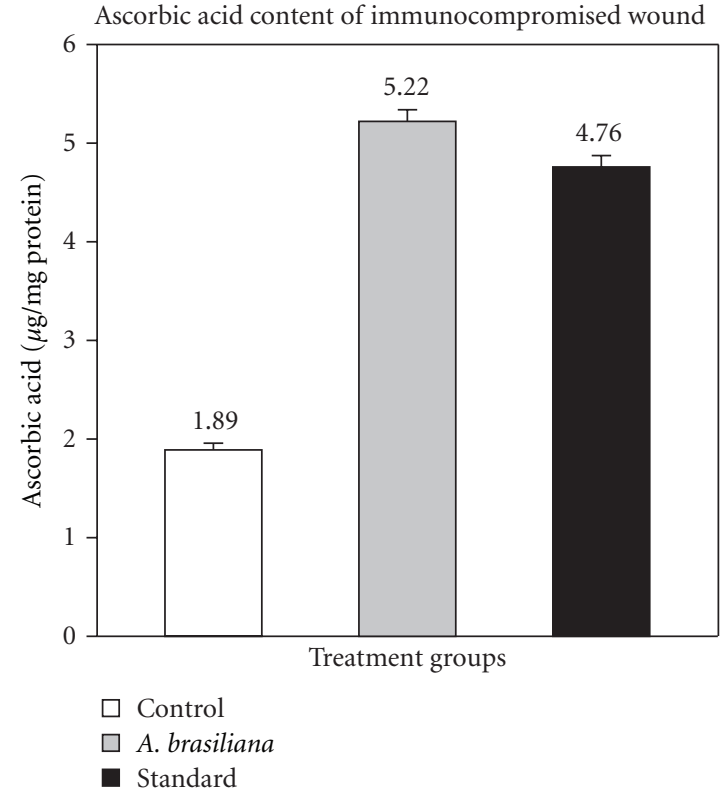

FIGURE 6: Effect of methanol extract of Alternanthera brasiliana on ascorbic acid content of granulation tissues in immunocompromised rats $(n=6$, each bar represents mean $\pm \mathrm{SE}, P<0.05$ versus vehicle, one-way ANOVA).

the 8 th day following wounding revealed proliferation of collagen fibers and angiogenesis $(\mathrm{H} \& \mathrm{E} \times 100)($ Figure $7(\mathrm{e}))$.

\section{Discussion}

The results of the present study clearly demonstrated that MEAB possessed a definite prohealing action in immunocompromised wound healing as observed by significant increase in the rate of wound contraction, augmented enzymatic and nonenzymatic antioxidant levels, and total protein contents in the granulation tissue, which was also supported by histopathological study. Triterpenes are known to promote the wound healing process mainly due to their astringent and antimicrobial property, which seems to be responsible for wound contraction and increased rate of epithelialization [22]. Possibly, the constituents like triterpenes and alkaloids of $A$. brasiliana may play major role in the process of wound healing. However, wound contraction and period of epithelization in immunocompromised animals were lesser than excision wound in normal animals and healing by epithelization was also delayed in this study as it was an impaired wound.

Myofibroblasts are believed to play a key role in wound contraction by exerting tension on the surrounding extracellular matrix (ECM) and secreting ECM proteins such as collagen to stabilize the contraction [23]. A. brasiliana promoted wound healing, which might be due to fibroblast proliferation and deposition of abundance of collagen fibers as evidenced by histopathological examination of granulation tissue. 


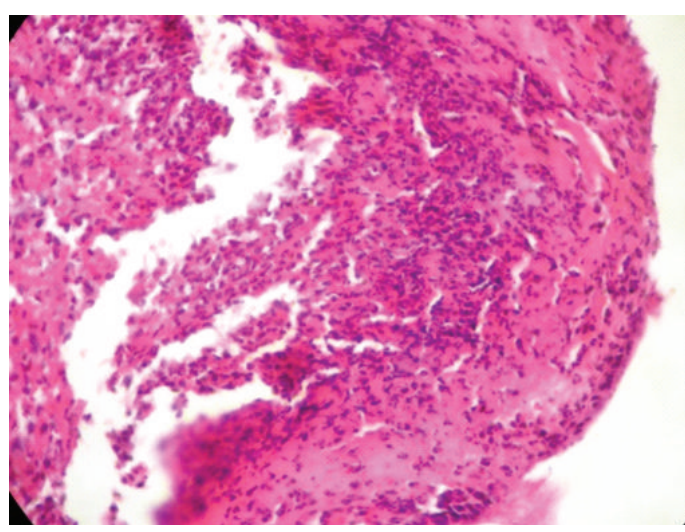

(a)

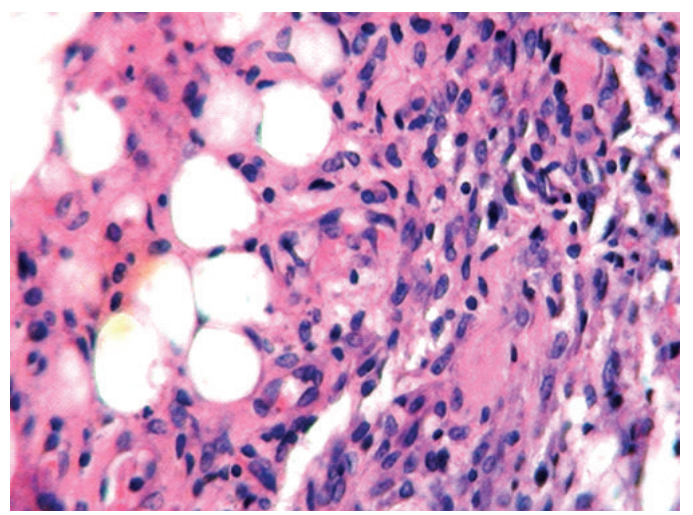

(c)

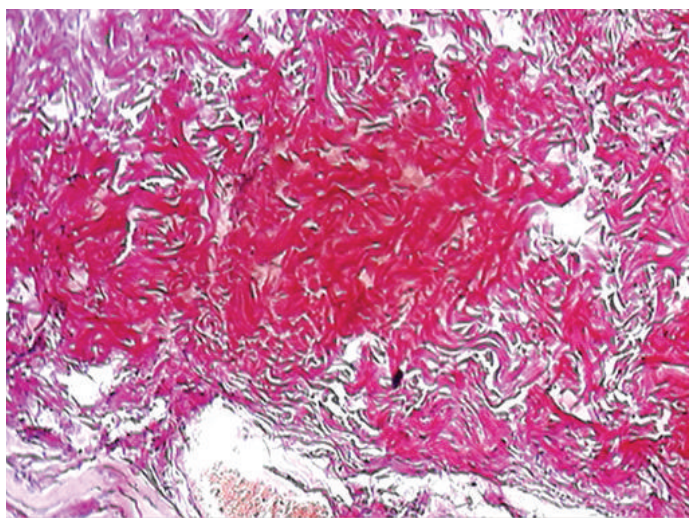

(b)

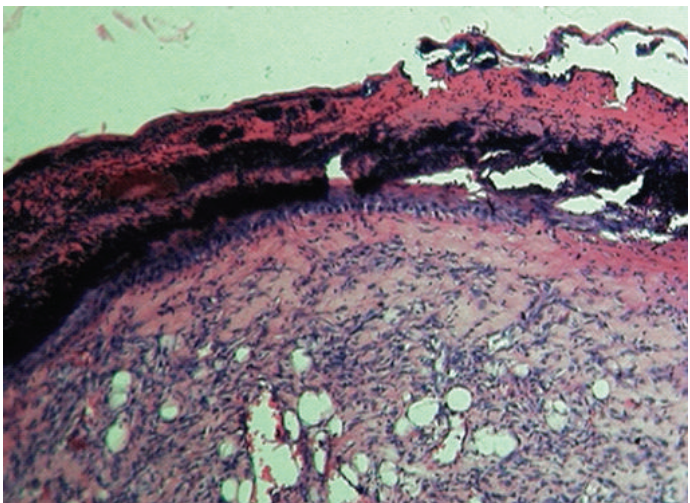

(d)

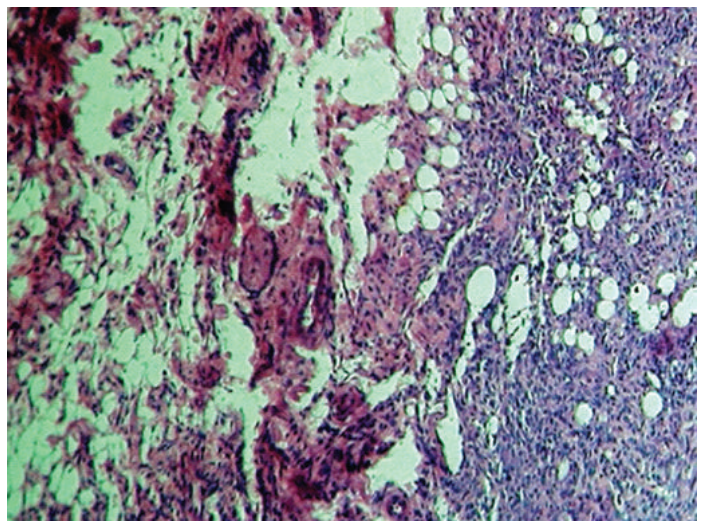

(e)

Figure 7: Photomicrograph showing histopathological changes of the granulation tissues on the 8th day following wounding in immunocompromised wound in rats. (a) Necrosis and polymorphonuclear cell infiltration $(\mathrm{H} \& \mathrm{E} \times 400)$ in control group. (b) Abundance of collagen fibers (Van Gieson's $\times 100)$ in A. brasiliana-treated group. (c) Fibroblast proliferation and angiogenesis $(\mathrm{H} \& \mathrm{E} \times 100)$ in $A$. brasiliana-treated group.(d) Development of basement membrane below the necrotic debris $(\mathrm{H} \& \mathrm{E} \times 100)$ in A. brasiliana-treated group. (e) Angiogenesis and collagen fibers $(\mathrm{H} \& \mathrm{E} \times 100)$ in Himax-treated standard group.

Angiogenesis is a critical component of wound healing. Delayed or aberrant revascularization at the wound sites contributes to the etiology of chronic wounds [24]. In our previous study on wound healing activity of MEAB, by in vivo (excision and incision wound) as well as in vitro chick Chorioallantoic membrane model in normal wound [5], significantly higher rate of wound contraction, tensile strength, and increased angiogenesis were reported as compared to the control group. In the present study also, histopathological studies of granulation tissues of $A$. brasiliana-treated group revealed angiogenesis, thus corroborating the previous findings.

Preventive antioxidants, such as super oxide dismutase (SOD), glutathione peroxidase, and catalase (CAT), are 
the first line of defence against ROSs [25]. The constituents present in the A. brasiliana extract might be responsible for promoting the collagen formation at the proliferative stage of wound healing. Histopathological study showed better proliferation of collagen fibers in the extract-treated group compared to the standard drug (Himax). In the present study, significant increase in the hydroxyproline content of the granulation tissue of the animals treated with A. brasiliana indicates enhanced collagen maturation by increased cross-linking.

The skin is a biological interface with the environment and is frequently and directly exposed to prooxidative stimuli including chemical oxidants, ultraviolet and visible irradiation, which are known to promote the generation of reactive oxygen species (ROS) and lipid peroxides [26]. Antioxidants like super oxide dismutase (SOD), catalase (CAT), and glutathione (GSH) in granulation tissues hasten the process of wound healing by destroying the free radicals [27].

Levels of different enzymatic and nonenzymatic antioxidants increased significantly after treatment with $A$. brasiliana. These findings suggest that decreased oxidative injury in the wound tissue could be due to increased quenching or scavenging of oxygen free radicals by the elevated levels of antioxidants. SOD-1 is a key enzyme in the dismutation of the potentially toxic super oxide radicals into hydrogen peroxide and dioxygen [28]. The effects of ascorbic acid on collagen synthesis, antioxidant status, and immunomodulation make it an appropriate supplement for wound repair protocols [29]. The increased ascorbic acid in the extract treated group might be responsible for protecting the cells from oxidative stress leading to better wound healing. The levels of enzymatic and nonenzymatic antioxidant enzymes were augmented in the treated group; however, another study conducted by us in diabetic wound model revealed significantly $(P<0.05)$ increased level of antioxidant enzymes, that is, SOD, GSH, vitamin C, and catalase in the treated group compared to the control group and level of catalase was even more compared to the standard- drug- (Himax-) treated group indicating promising wound healing activity of MEAB in diabetic wound model (communicated). Again in burn wound model antioxidant enzymes, that is, SOD, GSH, vitamin C, and catalase, were found to be significantly $(P<0.05)$ increased in the MEAB-treated group compared to the control group and all these antioxidant enzymes except vitamin $C$ were significantly $(P<0.05)$ increased compared to the standard drug also (communicated).

\section{Conclusion}

In conclusion, it can be interpreted that topical application of $A$. brasiliana exhibited significant wound healing activity in immunocompromised wound as evidenced by augmented endogenous antioxidants and increased angiogenesis. Further pharmacodynamic investigations are required to identify the active fractions responsible for its wound healing activity for formulation of a plant-based herbal product preserving the indigenous heritage with enormous beneficial value to the society.

\section{Acknowledgments}

This work was supported by the Defence Research Development Organization (DRDO), Government of India, Ministry of Defence, New Delhi. The authors are also grateful to the Director of Research (Vety) and Central Instrument Facility, C. V. Sc, Khanapara for providing facility to conduct the research.

\section{References}

[1] A. L. Leonard and C. W. Hanke, "Second intention healing for intermediate and large postsurgical defects of the lip," Journal of the American Academy of Dermatology, vol. 57, no. 5, pp. 832-835, 2007.

[2] D. J. Rosen, M. K. Patel, K. Freeman, and P. R. Weiss, "A primary protocol for the management of ear keloids: results of excision combined with intraoperative and postoperative steroid injections," Plastic and Reconstructive Surgery, vol. 120, no. 5, pp. 1395-1400, 2007.

[3] A. Gupta, G. K. Jain, and R. Raghubir, "A time course study for the development of an immunocompromised wound model, using hydrocortisone," Journal of Pharmacological and Toxicological Methods, vol. 41, no. 4, pp. 183-187, 1999.

[4] I. K. Cohen, R. F. Diegelmann, and M. L. Johnson, "Effect of corticosteroids on collagen synthesis," Surgery, vol. 82, no. 1, pp. 15-20, 1977.

[5] C. C. Barua, A. Talukdar, S. A. Begum et al., "Wound healing activity of methanolic extract of leaves of Alternanthera brasiliana Kuntz using in vivo and in vitro model," Indian Journal of Experimental Biology, vol. 47, no. 12, pp. 1001-1005, 2009.

[6] C. D. O. Brochado, A. P. De Almeida, B. P. Barreto et al., "Flavonol robinobiosides and rutinosides from Alternanthera brasiliana (Amaranthaceae) and their effects on lymphocyte proliferation in vitro," Journal of the Brazilian Chemical Society, vol. 14, no. 3, pp. 449-451, 2003.

[7] A. F. Macedo, N. C. Barbosa, M. A. Esquibel, M. M. Souza, and V. Cechinel-Filho, "Pharmacological and phytochemical studies of callus culture extracts from Alternanthera brasiliana," Pharmazie, vol. 54, no. 10, pp. 776-777, 1999.

[8] M. W. Bivattti, M. H. Bellever, L. Valpato, C. Costa, and C. Bellaver, "Preliminary studies of alternative feed additives for broilers: Alternanthera brasiliana extract, propolis extract and linseed oil," Revista Brasileira de Ciência Avícola, vol. 5, no. 2, pp. 1516-1635, 2003.

[9] M. H. C. Lagrota, M. D. Wigg, M. M. G. Santos et al., "Inhibitory activity of extracts of Alternanthera brasiliana (Amaranthaceae) against the herpes simplex virus," Phytotherapy Research, vol. 8, no. 6, pp. 358-361, 1994.

[10] H. Wagner, S. Bladt, and E. M. Zgainski, Plant Drug Analysis, Springer, Berlin, Germany, 1984.

[11] C. C. Barua, A. Talukdar, S. A. Begum, D. K. Sarma, D. C. Pathak, and P. Borah, "Antinociceptive activity of methanolic extract of leaves of Alternanthera brasiliana Kuntz. in animal models of nociception," Pharmacologyonline, vol. 3, pp. 49-55, 2009.

[12] J. B. Harborn, Phytochemical Methods: A Guide to Modern Techniques of Plant Analysis, Chapman \& Hall, London, UK, 2nd edition, 1991.

[13] J. J. Morton and M. H. Malone, "Evaluation of vulneray activity by an open wound procedure in rats," Archives Internationales de Pharmacodynamie et de Therapie, vol. 196, no. 1, pp. 117-126, 1972. 
[14] N. K. Upadhyay, R. Kumar, S. K. Mandotra et al., "Safety and healing efficacy of Sea buckthorn (Hippophae rhamnoides L.) seed oil on burn wounds in rats," Food and Chemical Toxicology, vol. 47, no. 6, pp. 1146-1153, 2009.

[15] J. F. Woessner Jr., "The determination of hydroxyproline in tissue and protein samples containing small proportions of this imino acid," Archives of Biochemistry and Biophysics, vol. 93, no. 2, pp. 440-447, 1961.

[16] O. H. Lowry, N. J. Rosenburgh, A. L. Farr, and R. J. Randell, "Protein measurement with the Folin phenol reagent," The Journal of Biological Chemistry, vol. 193, no. 1, pp. 265-275, 1951.

[17] E. Beutler, O. Duron, and B. M. Kelly, "Improved method for the determination of blood glutathione," The Journal of Laboratory and Clinical Medicine, vol. 61, pp. 882-888, 1963.

[18] S. Marklund and G. Marklund, "Involvement of the superoxide anion radical in the autoxidation of pyrogallol and a convenient assay for superoxide dismutase," European Journal of Biochemistry, vol. 47, no. 3, pp. 469-474, 1974.

[19] H. Aebi, Catalase, and H. U. Bergmeyer, Eds., Methods of Enzymatic Analysis, Academic Press, New York, NY, USA, 1984.

[20] J. H. Rae, "Chemical determination of ascorbic acid, dehydroascorbic acid and diketogluconic acids," in Methods of Biochemical Analysis, Q. Glick, Ed., Interscience, New York, NY, USA, 1984.

[21] G. Lee and H. T. Luna, Manual of Histological Staining Methods of the Armed Forces, Institute of Pathology, American Registry of Pathology, Blakiston Division, New York, NY, USA, 3rd edition, 1968.

[22] R. A. F. Clark, Cutaneous Wound Repair, vol. 199, Oxford University, New York, NY, USA.

[23] B. S. Nayak, S. Sandiford, and M. Anderson, "Evaluation of the wound-healing activity of ethanolic extract of Morinda citrifolia L. leaf," Evidence-Based Complementary and Alternative Medicine, vol. 6, no. 3, pp. 351-356, 2007.

[24] N. K. Upadhyay, R. Kumar, M. S. Siddiqui, and A. Gupta, "Mechanism of wound-healing activity of Hippophae rhamnoides L. leaf extract in experimental burns," Evidence-Based Complementary and Alternative Medicine, vol. 2011, Article ID 659705, 9 pages, 2011.

[25] A. Gupta, N. K. Upadhyay, R. C. Sawhney, and R. Kumar, "A poly-herbal formulation accelerates normal and impaired diabetic wound healing," Wound Repair and Regeneration, vol. 16, no. 6, pp. 784-790, 2008.

[26] A. J. Singer and R. A. F. Clark, "Cutaneous wound healing," The New England Journal of Medicine, vol. 341, no. 10, pp. 738746, 1999.

[27] A. Gupta, R. L. Singh, and R. Raghubir, "Antioxidant status during cutaneous wound healing in immunocompromised rats," Molecular and Cellular Biochemistry, vol. 241, no. 1-2, pp. 1-7, 2002.

[28] B. Halliwell, M. Grootveld, and J. M. Gutteridge, "Methods for the measurement of hydroxyl radicals in biomedical systems: deoxyribose degradation and aromatic hydroxylation," Methods of biochemical analysis, vol. 33, pp. 59-90, 1988.

[29] I. Fridovich, "The biology of oxygen radicals," Science, vol. 201, no. 4359, pp. 875-880, 1978. 

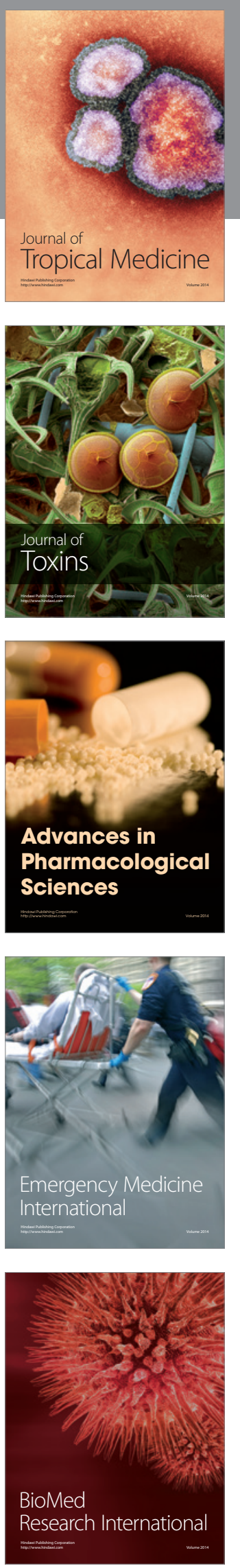
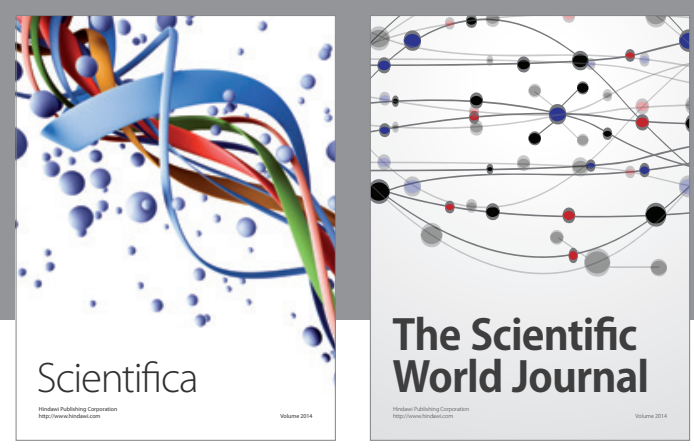

The Scientific World Journal
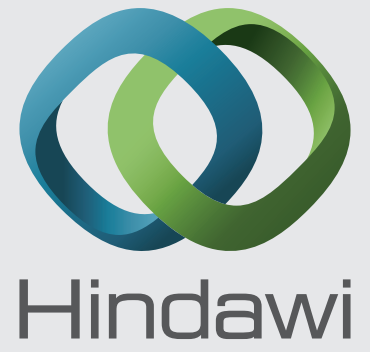

Submit your manuscripts at

http://www.hindawi.com
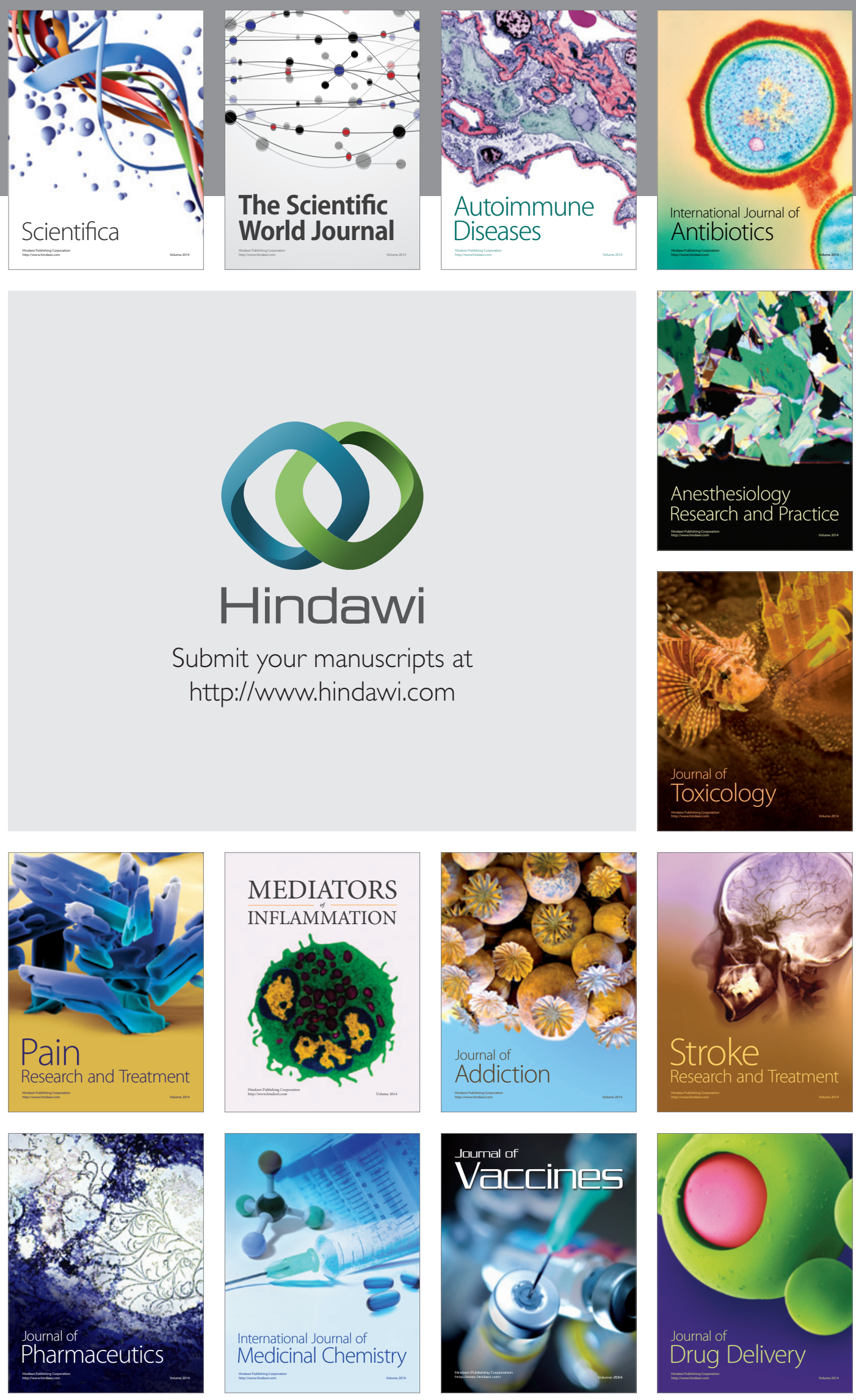